\title{
Assessment of Native Pink Pigmented Facultative Methylotrophs of Chilli (Capsicum annuum L.) for their Plant Growth Promotional Abilities
}

\author{
Savitha Santosh $^{1,2 *}$, H.B. Santosh ${ }^{1}$ and M.N. Sreenivasa ${ }^{2}$ \\ ${ }^{1}$ ICAR - Central Institute for Cotton Research (CICR), Nagpur, Maharashtra - 440010, India \\ ${ }^{2}$ Department of Agricultural Microbiology, University of Agricultural Sciences (UAS), \\ Dharwad, Karnataka - 580005, India \\ *Corresponding author
}

\section{A B S T R A C T}

Keywords

Capsicum annuum,

Chilli,

Methylotrophs,

PPFM,

Phytohormones,

Phosphate

solubilisation

Article Info

Accepted:

10 December 2018

Available Online:

10 January 2019
Investigations were carried out to study the plant growth promotional ability of native pink pigmented facultative methylotrophs (PPFMs) of major chilli (Capsicum annuиm L.) growing areas of North Karnataka. Selected isolates were screened for beneficial characters like production of phytohormones, phosphate solubilisation and siderophore production. Highest indole 3 acetic acid and gibberellic acid production was recorded in PPFM6, 19.77 and $128.28 \mu \mathrm{g} / \mathrm{ml}$ of culture filtrate, respectively. The strain PPFM170 recorded highest cytokinin production $(2.54 \mu \mathrm{g} / \mathrm{ml})$. Mineral phosphate solubilisation index was in the range of 0.31 to 0.97 and the isolate PPFM6 produced higher amount of inorganic phosphorous at 5 days after incubation $(6.5 \%)$ and even at 10 days after incubation $(8.99 \%)$. The production of catechol type of siderophores was observed among PPFM isolates which ranged from 0.2 to $0.61 \mu$ moles of Di Hydroxy Benzoic Acid. The present study has identified potential native PPFM strains from major chilli growing districts of North Karnataka for their exploration in improving production and productivity of chilli.

\section{Introduction}

Methylotrophs are those microorganisms which are able to grow utilizing the reduced carbon compounds, like methanol (released during plant metabolism), containing one or more carbon atoms having no carbon-carbon bonds. Obligate methylotrophs grow only on such compounds whereas, facultative methylotrophs thrive on a variety of other organic multi-carbon compounds (Anthony,
1982). Different species of methylotrophs are distributed in a diverse variety of natural and manmade environments, including soil, air, dust, fresh water, marine water, water supplies, polluted soil, bathrooms, air conditioning systems, masonry, etc. (Trotsenko et al., 2001). Several species of methylotrophic bacteria are found growing in association with terrestrial and aquatic plants, colonizing roots, leaf surfaces and growing buds (Lidstrom and Chistoserdova, 2002). The 
structural and functional diversity of microorganisms on the plant surface differ among the plant species due to differences in their exudates. The pink-pigmented facultative methylotrophs (PPFMs) are widely distributed in nature and are particularly known for their close association with plants (Lidstrom and Christoserdova, 2002; Lodewyckx et al., 2002).

The natural occurrence of PPFM with varied population intensities among different vegetable crops viz., tomato, chilli, eggplant, bitter gourd, bhendi, coccinia, cucumber, cauliflower, radish and mint at flowering stage has been reported (Anurajan, 2003). The spatial distribution of PPFM on various vegetable leaves like eggplant, green perilla, small green pepper, pumpkin, bitter melon, okra, and tomato has also been studied (Mizuno et al., 2012). Several beneficial aspects such as stimulation of seed germination, plant growth promotion, production of phytohormones and induction of defense responses in rice and peanut against Rhizoctonia solani, Aspergillus niger and Sclerotium rolfsi have been reported for Methylobacterium (Omer et al., 2004; Madhaiyan et al., 2004; 2006a). They influence plant growth by producing auxins (Doronina et al., 2002) and cytokinins (Koenig et al., 2002). In addition, they can fix atmospheric nitrogen (Jourand et al., 2004), bring about mineral phosphate solubilisation (Jones et al., 2007), regulate the ethylene level in rhizosphere by 1-aminocyclopropane-1carboxylate deaminase (Madhaiyan et al., 2006b) and stimulate the resistance against plant pathogens (Madhaiyan et al., 2006a).

Often, the bio inoculants used for crop plants as plant growth promoters are isolated generally from rhizosphere soil and deserving attention has not been paid to the phyllosphere microorganisms and very few studies have focussed on studies on bio inoculants in chilli.
Hence, by considering the importance of PPFM as plant growth promoting bacteria, we isolated and identified the native isolates of PPFM from chilli fields of major chilli growing districts of north Karnataka in order to assess their growth promotional ability through phytohormones production, phosphate solubilisation and siderophores production so that they can be further be utilized as potential bioinoculants to improve the growth, yield and quality of chilli.

\section{Materials and Methods}

The samples of rhizosphere soils, roots and phyllosphere were collected from chilli fields of major chilli growing districts of North Karnataka viz., Dharwad, Gadag and Haveri (Table 1) for isolation of PPFM. They were isolated by leaf imprinting and serial dilution technique (Savitha et al., 2013) and putatively identified as PPFM based on pink pigmented colonies on ammonium mineral salts (AMS) agar media with methanol as sole source of carbon and energy. All the isolates were initially screened for qualitative production of indole 3 acetic acid (John et al., 1991) and their ability to inhibit the growth of Colletotrichum capsici on agar plates by dual culture technique (Ganesan and Gnanamanikyam, 1987). The positive isolates were further subjected for quantitative estimation of phytohormones, $\mathrm{P}$ - solubilization and siderophores production.

\section{Production of phytohormones by PPFM isolates}

The production of phytohormones was estimated by extracting the cell free culture filtrate of PPFM twice with equal amount of ethyl acetate (Tien et al., 1979) and used for quantification of indole-3 acetic acid (IAA) and cytokinin through high performance liquid chromatography (HPLC) (Tien et al., 1979; Omer et al., 2004). Gibberellic acid (GA) 
production was estimated through Spectrophotometry (Mahadevan and Sridhar, 1986).

Qualitative and quantitative estimation of siderophores

PPFM isolates were grown on iron deficient AMS medium and culture filtrate was separated from cells by centrifugation at 7000 rpm for 20 min. Both catechol and hydroxamate type of siderophores produced were extracted (Modi et al., 1985). Unit volume of the Hathway's reagent (Reeves et al., 1983) was added to same volume of the sample and development of wine or orange colour was noted as the presence of catechol and hydroxamate type of siderophores, respectively. The development of wine colour was read in spectrophotometer at $700 \mathrm{~nm}$ with 2, 3-dihydroxy benzoic acid as standard for quantification of catechol type of siderophores. While hydroxamate siderophores were measured according to Csaky (1948).

\section{Screening of PPFM isolates for mineral phosphate solubilisation (MPS) activity}

The isolates were subjected for preliminary phosphate solubilization on Pikovskaya's medium with tricalcium phosphate (TCP) as insoluble source of phosphorous and the $\mathrm{pH}$ of the media was adjusted to 7.0. The zone of phosphate solubilization was observed after 10 days after incubation (DAI) and solubilization index was calculated (Seshadri et al., 2002). The quantification of inorganic phosphate $(P i)$ released from TCP in broth was estimated on $5^{\text {th }}$ and $10^{\text {th }}$ DAI by phosphomolybdic blue colour method (Jackson, 1973) and change in $\mathrm{pH}$ was also recorded.

\section{Results and Discussion}

A total 200 PPFM strains were isolated on AMS agar media from more than 250 samples collected from chilli fields of major chilli growing districts of North Karnataka and coded as PPFM series. Of the total 200 isolates obtained, 30 isolates were found positive for IAA production and 9 revealed antagonistic activity against $C$. capsici. Morphological characterization of these isolates showed differential pink pigmentation when grown on AMS agar media (Table 1). These 30 shortlisted isolates were further evaluated for quantitative production of IAA, GA and cytokinins, P-solubilisation ability and siderophore production. Among 30 isolates, all of them showed differential phytohormones production, eight were showing MPS activity and nine isolates were positive for siderophores production. So these nine best PPFM isolates which were having characteristic of PGPR were further shortlisted and presented here.

\section{Production of phytohormones by PPFM isolates}

The production of IAA significantly varied with different isolates (Fig. 1A) and the highest IAA production of $19.77 \square \mathrm{g} / \mathrm{ml}$ of culture filtrate was recorded for PPFM6 and lowest was recorded for PPFM85 (1.27 $\square \mathrm{g} / \mathrm{ml}$ ). HPLC chromatogram for retention time of IAA is presented in Figure 2. For GA production, highest value was recorded for PPFM6 (128.28 $\square \mathrm{g} / \mathrm{ml})$ whereas, lowest was observed in PPFM85 (30.10 $\square \mathrm{g} / \mathrm{ml}$ ) (Fig 1B). PPFM170 produced significantly higher Cytokinin (2.54 $\square \mathrm{g} / \mathrm{ml}$ ) compared to other isolates (Fig. 1C). Production of cytokinin was confirmed through HPLC (Fig. 3).

\section{Siderophores production}

Out of 30 isolates tested, nine were positive for siderophore production and development of wine color in all isolates indicated production of catechol type of siderophores by PPFM isolates. The absence of orange color conveyed isolates inability to produce 
hydroxymate type of siderophores. The PPFM isolates which were found to produce the catechol type of siderophore were further quantified for the production of siderophores and was expressed as $\mu$ moles of Di Hydroxy
Benzoic Acid (DHBA). The amount of siderophore production ranged from 0.2 to $0.61 \mu$ moles of DHBA (Fig. 4).

Table.1 Morphological characteristics of selected PPFM isolate

\begin{tabular}{|l|l|l|l|l|}
\hline Isolates & Habitat & Place & GPS Location & Pigmentation \\
\hline PPFM 6 & Phyllosphere & Annigeri & 15.434833 N, 75.440369 E & Dark pink \\
\hline PPFM 35 & Root endophyte & Amminabhavi & 15.545342 N, 75.049431 E & Pale pink \\
\hline PPFM 38 & Root endophyte & Sulla & 15.451612 N, 75.173586 E & Medium pink \\
\hline PPFM 65 & Root endophyte & Navalgund & 15.548526 N, 75.344917 E & Medium pink \\
\hline PPFM 85 & Root endophyte & Lakshmeshwar & 15.137514 N, 75.469916 E & Pale pink \\
\hline PPFM99 & Phyllosphere & Belavanki & 15.667781 N, 75.566872 E & Dark pink \\
\hline PPFM 140 & Phyllosphere & Devaragudda & 14.666920 N, 75.572186 E & Pale pink \\
\hline PPFM 155 & Root endophyte & Masangi & 14.668410 N, 75.427936 E & Medium pink \\
\hline PPFM170 & Phyllosphere & Savanur & 14.967365 N, 75.327599 E & Dark pink \\
\hline
\end{tabular}

Table.2 Phosphate solubilisation of shortlisted PPFM isolates on Pikovskaya's media

\begin{tabular}{|l|l|l|l|l|l|}
\hline $\begin{array}{l}\text { Isolates code } \\
\text { No. }\end{array}$ & $\begin{array}{l}\text { Phosphate } \\
\text { Solubilisation } \\
\text { Index }\end{array}$ & \multicolumn{2}{|c|}{ Final pH } & \multicolumn{2}{|c|}{$\begin{array}{l}\text { Per cent } \\
\text { Pi released }\end{array}$} \\
\cline { 3 - 6 } & $\mathbf{5}$ ays & $\mathbf{1 0}$ Days & 5 Days & 10 Days \\
\hline PPFM 6 & 0.97 & 4.20 & 3.20 & $6.50(14.77)$ & $8.99(17.45)$ \\
\hline PPFM 35 & 0.55 & 4.50 & 3.60 & $6.10(14.30)$ & $7.50(15.89)$ \\
\hline PPFM 38 & 0.47 & 5.40 & 5.00 & $4.20(11.83)$ & $4.52(12.27)$ \\
\hline PPFM 65 & 0.33 & 5.30 & 4.80 & $4.70(12.52)$ & $5.00(12.92)$ \\
\hline PPFM 99 & 0.42 & 4.80 & 4.50 & $5.40(13.44)$ & $5.80(13.94)$ \\
\hline PPFM 140 & 0.70 & 5.00 & 4.65 & $5.10(13.05)$ & $5.45(13.50)$ \\
\hline PPFM 155 & 0.31 & 5.60 & 5.20 & $3.80(11.24)$ & $4.00(11.54)$ \\
\hline PPFM 170 & 0.92 & 4.30 & 3.40 & $6.40(14.65)$ & $8.20(16.64)$ \\
\hline SEm \pm & 0.01 & 0.01 & 0.02 & 0.07 & 0.09 \\
\hline CD $(\mathbf{0 . 0 1})$ & 0.03 & 0.05 & 0.07 & 0.31 & 0.40 \\
\hline Not & & & & &
\end{tabular}

Note: Arc sine transformed values are represented in parentheses 
Fig.1 Production of phytohormones (A) IAA (B) GA and (C) Zeatin by PPFM isolates
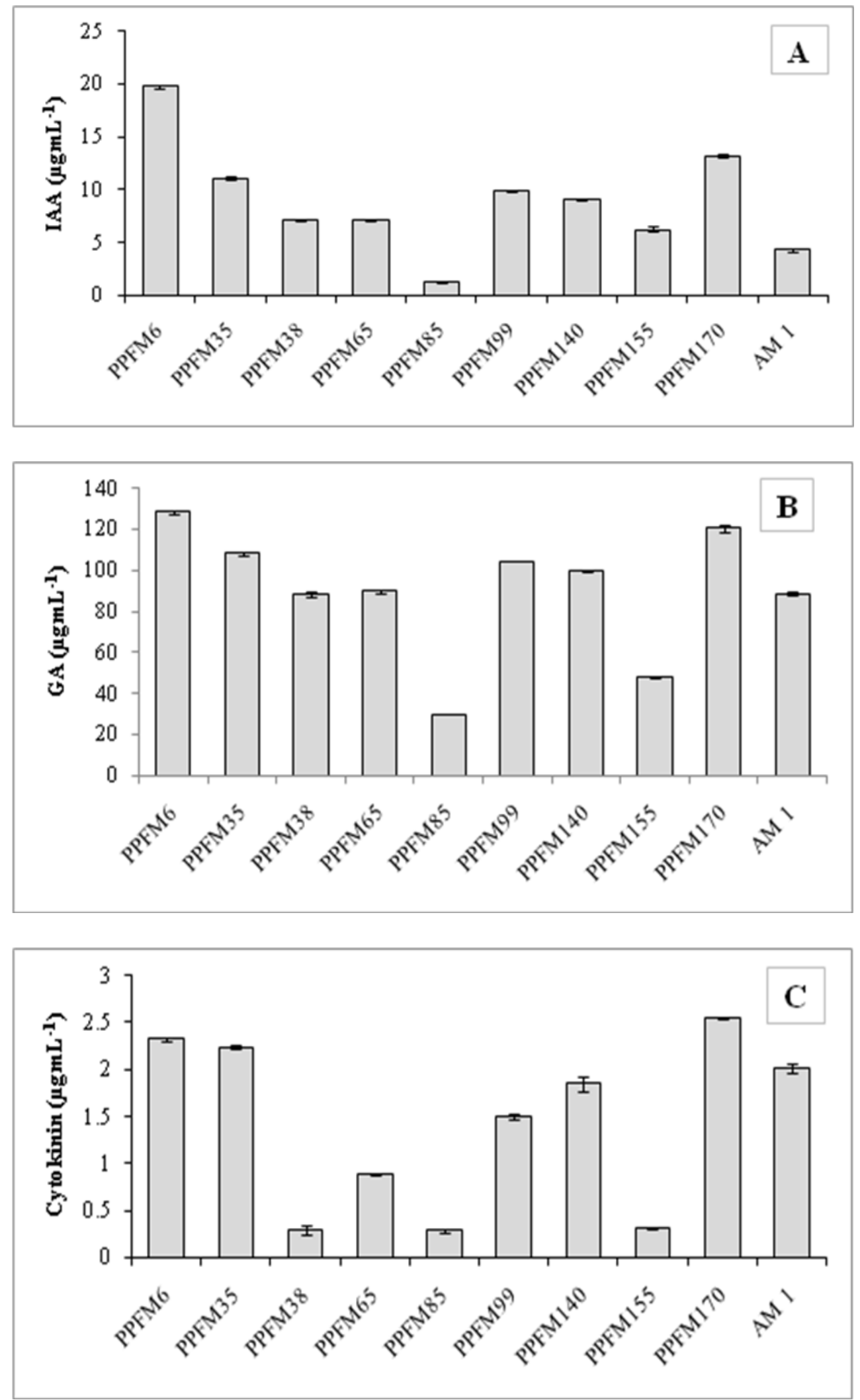
Fig.2 HPLC chromatogram of IAA produced by native PPFM isolate

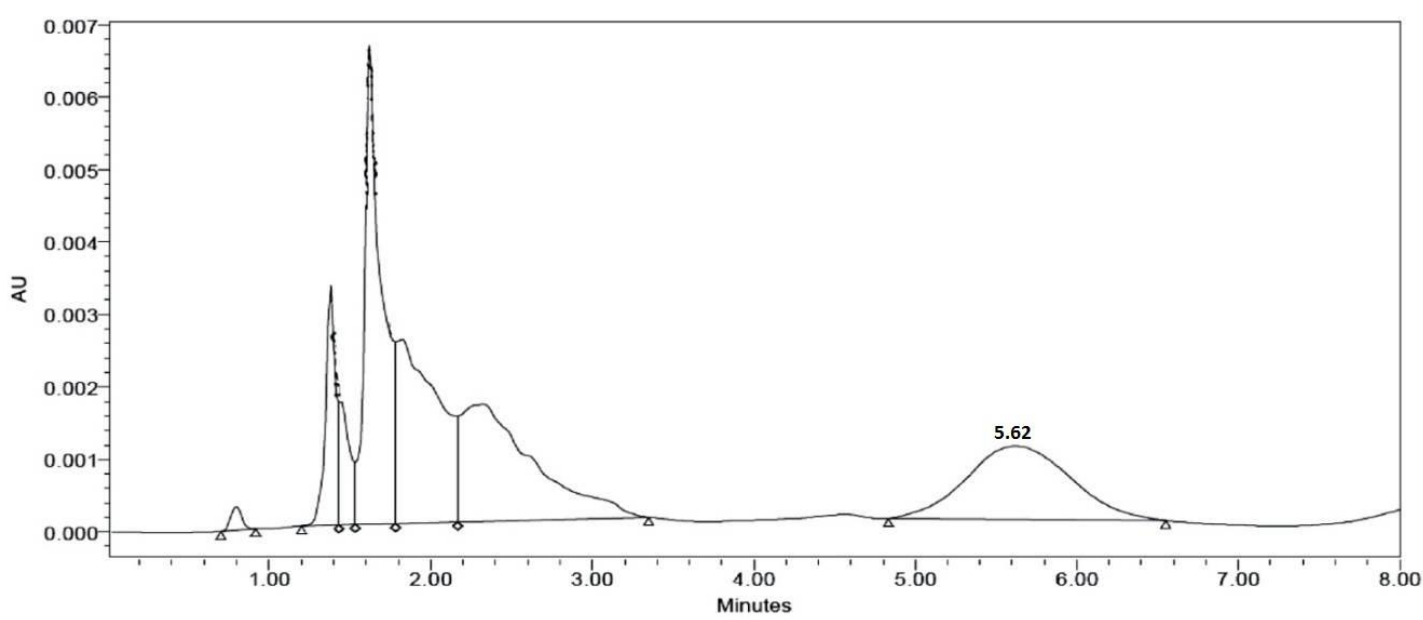

Fig.3 HPLC chromatogram of cytokinin (zeatin) produced by native PPFM isolate

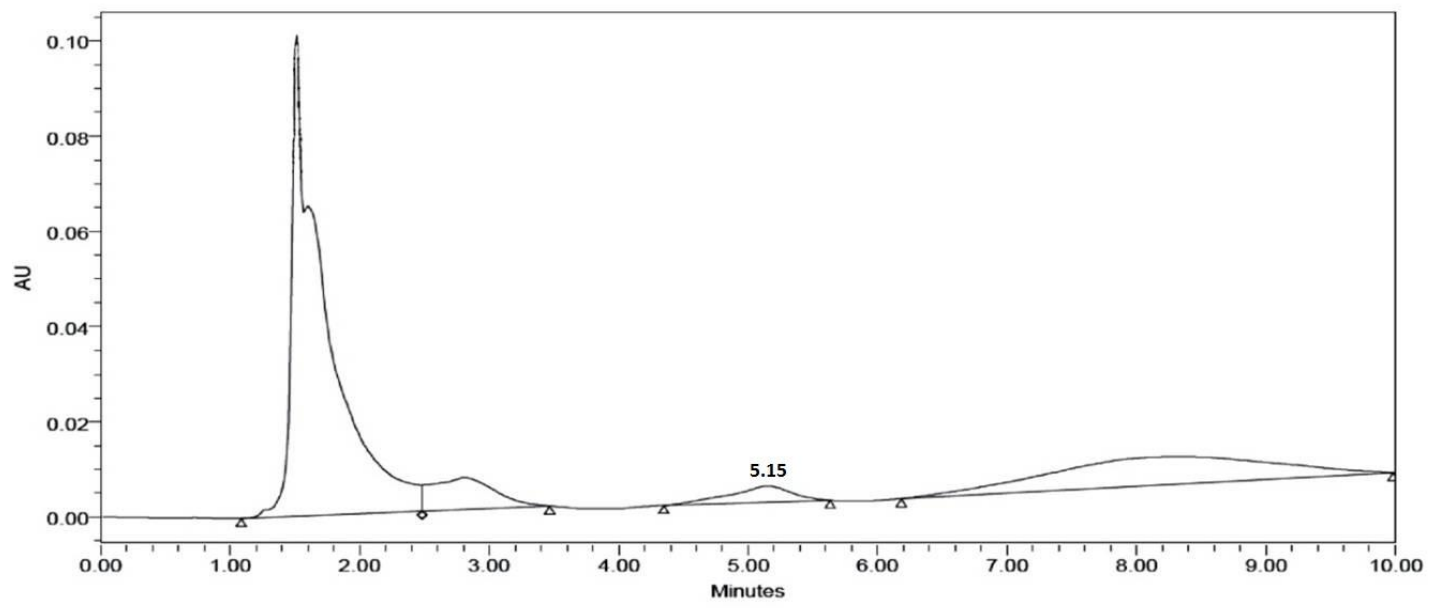

Fig.4 Quantitative estimation of siderophore produced by PPFM isolates

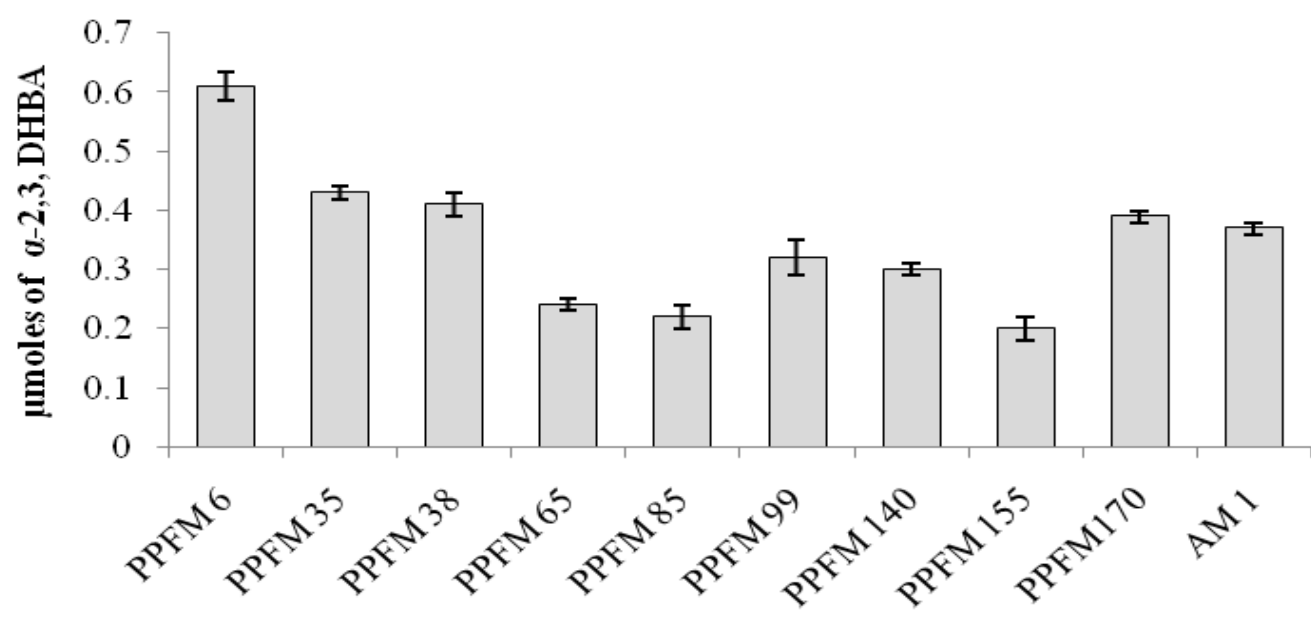




\section{Phosphate solubilisation by PPFM isolates}

Out of 30 isolates tested for $\mathrm{P}$ solubilisation ability, eight isolates revealed MPS activity. Phosphate solubilisation ability of PPFM isolates is expressed as phosphate solubilisation index (PSI), which ranged from 0.31 to 0.97 . Gradual increase in $P i$ release from $5^{\text {th }}$ to $10^{\text {th }}$ DAI as observed. The isolate PPFM6 produced higher amount of $P i$ both at $5^{\text {th }}$ DAI $(6.5 \%)$ and 10 DAI $(8.99 \%)$. While reference strain Methylobacterium extorquens AM1 didn't show any MPS activity. Further decrease in $\mathrm{pH}$ was observed with higher amount of $P i$ released in all isolates. The drastic reduction in $\mathrm{pH}$ from 7 to 4.2 and 3.2 was found at 5DAI and 10DAI respectively, was observed in isolate PPFM6 (Table 2).

In the present study PPFMs isolated from chilli rhizopshere soil, roots and phyllosphere were screened for ability to produce phytohomones like IAA, GA and cytokinins. The isolates tested produced phytohormones in varying quantities. The amount of IAA produced was ranging from 1.27 to 19.77 $\square \mathrm{g} / \mathrm{ml}$ of culture filtrate, GA was in the range of 30.10 to $128.28 \square \mathrm{g} / \mathrm{ml}$ of culture filtrate and cytokinin produced was ranging from 0.29 to $2.54 \square \mathrm{g} / \mathrm{ml}$ of culture filtrate.

This varied production of phytohormones is strain-dependent and therefore a "species-specific" characteristic. The isolate which is able to produce significantly higher amount of phytohormones known to perform better with respect to improving growth and yield of crop plants.

The IAA is produced and secreted by different strains of Methylobacterium (Doronina et al., 2002; Ivanova et al., 2001; Hornscluh et al., 2006 and Kutschera, 2007). However, the first report on the production IAA in significant amount by methylotrophs was given by Ivanova et al., (2001).
Omer et al., (2004) unambiguously confirmed that PPFM produced plant hormone IAA through HPLC and Nuclear magnetic resonance. Production of GA was varying among different isolates as reported by Anurajan (2003) (10.9 to $106.97 \mu \mathrm{g} / \mathrm{ml}$ ), Thangamani (2005) $(28.86 \mu \mathrm{g} / \mathrm{ml}$ to 98.26 $\mu \mathrm{g} / \mathrm{ml}$ ), Radha (2007) (24.11 to $70.30 \mu \mathrm{g} / \mathrm{ml}$ ) and Jones (2010) (53.20 to $273.20 \mu \mathrm{g} / \mathrm{ml}$ ). The GA production was estimated by spectrophotometry by Sheela et al., (2013) in PPFM isolates, where PPFM $14 \quad(59.13$ $\square \mathrm{g} / \mathrm{ml}$ ) isolate produced higher amount. Traditionally, the study of cytokinin production by plant-associated bacteria has been associated with microbes known to cause plant disease or to enter into an intimate symbiosis with a plant host. Koenig et al., (2002) sought to rectify the omission of plant commensal bacteria from this field of study by making a detailed examination of cytokinin production by PPFMs. Studies by Reddy (2002) revealed that the cytokinin production of PPFM leaf isolates ranged from 21.46 to $124.32 \mathrm{ng} / \mathrm{l}$ of culture filtrate.

Thangamani (2005) and Jones (2010) observed cytokinin production ranging from $0.147 \mathrm{ng} / \mathrm{l}$ to $11.27 \mathrm{ng} / \mathrm{l}$ and 0.07 to 1.84 $\mu \mathrm{g} / \mathrm{ml}$, respectively. Bacterial siderophores are low-molecular weight compounds with high $\mathrm{Fe}^{3+}$ chelating affinity (Sharma and Johri, 2003) responsible for the solubilization and transport of $\mathrm{Fe}^{3+}$ element into bacterial cells. Some bacteria produce hydroxamatetype siderophores while others produce catecholate-types (Neilands and Nakamura, 1991). The production of siderophores by microorganisms is beneficial to plants, because it can inhibit the growth of plant pathogens (Sharma and Johri, 2003). In the present study, PPFM isolates tested produced only catechol type of siderophore ranging from $0.20 \mu$ moles of DHBA to $0.61 \mu$ moles of DHBA. Similarly, Anurajan (2003), Senthilkumar (2003) and Vaidehi and Sekar 
(2012) observed catechol type of siderophore production by PPFMs.

In the present study, it was observed that longer incubation period increased the soluble $\mathrm{P}$ concentration in broth indicating the slow action of the PPFM strains under controlled conditions. Microbial growth associated with decrease in $\mathrm{pH}$ of the medium has been reported to be efficient for P-solubilization (Khan et al., 2006). In vitro studies have shown that $\mathrm{P}$ solubilisation can be associated with a marked drop in $\mathrm{pH}$, production of phosphatases and organic acids. In the present study significant decline in $\mathrm{pH}$ level indicates medium acidification responsible for $\mathrm{P}$ solubilisation (Whitelaw et al., 1999; Achal et al., 2007). A pH regime of 3.4-4.6 was reported to be enough for significant solubilization of the Ca-phosphate in the presence of various carbon sources (Whitelaw et al., 1999).

In conclusion, this study showed varied amount of phytohormones production, phosphate solubilisation and siderophores production by PPFM isolates isolated from chilli crop. So these PPFM isolates exhibit characteristics of plant growth promoting microorganisms. Based on our study, we propose further exploration of these identified potential PPFM isolates as bioinoculants in improvement of production and productivity of chilli crop.

\section{Acknowledgements}

Grant of financial assistance in the form of Senior Research Fellowship (SRF) by Indian Council of Agricultural Research (ICAR) is gratefully acknowledged.

\section{References}

Achal, V., Savant, V. V., and Reddy, M. S. 2007. Phosphate solubilization by a wild type strain and UV-induced mutants of
Aspergillus tubingensis. Soil Biol. Biochem. 39, 695-699.

Anthony, C. 1982. The biochemistry of methylotrophs. Academic Press, New York, N.Y.

Anurajan, S. 2003. Studies on the occurrence of pink pigmented facultative methylotrophs on vegetable crops. $M$. Sc. (Agri.) Thesis, Tamil Nadu Agricultural University, Coimbatore.

Csaky, T. Z. 1948. On the estimation of bound hydroxylamine in biological materials. Acta Chemica Scandinavica, 2, 450454.

Doronina, N. V., Ivanova, E. G. and Trotsenko, Y. A. 2002. New evidence for the ability of methylobacteria and methanotrophs to synthesize auxins. Microbiol. 71, 116-118.

Ganesan, P. and Gnanamanikyam, S. S. 1987. Biological control of Sclerotium rolfsii Sacc. in peanut by inoculation with Pseudomonas fluorescens. Soil Biol. Biochem. 19, 35-38.

Hornschuh, M., Grotha, R. and Kutschera, U. 2006. Moss-associated methylobacteria as phytosymbionts: An experimental study. Naturwissenschaften, 93, 480-486.

Ivanova, E. G., Doronina, N. V. and Trotsenko, Y. A. 2001. Aerobic methylobacteria are capable of synthesizing auxins. Microbiol. 70, 392-397.

Jackson, M. L., 1973, Soil Chemical Analysis, Prentice Hall of India Pvt. Ltd., New Delhi.

John M. B. C., Richard, M. B., and Sara, E. S. 1991. Rapid In Situ assay for Indoleacetic acid production by bacteria immobilized on a nitrocellulose membrane. Appl. Environ. Microbiol. 57, 535-538.

Jones, N. P. 2010. Molecular diversity of Arbuscular mycorrhizal fungi and pink pigmented facultative methylotrophic bacteria and their influence on grapevine (Vitis vinifera). Ph. D. (Agri.) Thesis, Univ. Agric. Sci., Dharwad (India). 
Jones, N. P., Krishnaraj, P. U., Kulkarni, J. H., Pranav, C., Alagawadi, A. R. and Vasudev, A. R. 2007. Pink pigmented facultative methylotrophs solubilize mineral phosphates. Paper presented at $48^{\text {th }}$ Annual Conf., AMI, held at IIT, Chennai, pp: 18-21.

Jourand, P., Giraud, E., Bena, G., Sy, A., Willems, A. and Gillis, M. 2004. Methylobacterium nodulans sp. nov., for a group of aerobic, facultatively methylotrophic, legume root nodule forming and nitrogen-fixing bacteria. Int. J. Syst. Evolu. Microbiol., 54, 2269 2273.

Khan, M. S., Zaidi, A and Wani, P. A. 2006. Role of phosphate solubilizing microorganisms in sustainable agriculture: a review. Agron. Sustain. Dev. 26, 1-15.

Koenig, R. L., Morris, R. O. and Polacco, J. C. 2002. tRNA is the source of low level trans-zeatin production in Methylobacterium spp. J. Bacteriol. 184, 1832-1842.

Kutschera, U. 2007. Plant-associated methylobacteria as co-evolved phytosymbionts. Plant Signal. Behav. 2, 74-78.

Lidstrom, M. E. and Chistoserdova, L. 2002. Plants in the pink: cytokinin production by Methylobacterium. J. Bacteriol. 184, 1818

Lodewyckx, C., Mergeay, M., Vangronsfeld, J., Clijsters, H. and Van der Lelie, D. 2002. Isolation, characterization, and identification of bacteria associated with the zinc hyper-accumulator Thlaspi caerulescens subsp. Calaminaria, Int. J. Phytoremediat. 4, 101-105.

Madhaiyan, M., Poonguzhali, S., Ryu, J. and Sa, T. 2006b. Regulation of ethylene levels in canola (Brassica campestris) by 1-aminocyclopropane-1-carboxylate deaminase - containing Methylobacterium fujisawaense. Planta. 224, 268-278.

Madhaiyan, M., Poonguzhali, S., Senthilkumar, M., Sundaram, S., Heekyung, C.,
Jinchul, Y., Subbiah, S. and Tongmin, S. A. 2004. Growth promotion and induction of systemic resistance in rice cultivar Co-47 (Oryza sativa L.) by Methylobacterium spp. Bot. Bull. Acad. Sin. 45, 315-324.

Madhaiyan, M., Suresh Reddy, B. V., Anandam, R., Senthilkumar, M., Poonguzhali, S. and Sundaram, S. P., 2006a. Plant growth promoting Methylobacterium induces defense responses in ground nut (Arachis hypogaea L.) compared with root pathogen. Curr. Microbiol. 53, 270276.

Mahadevan, A. and Sridhar, R. 1986. Methods in Physiological Plant Pathology. Sivakami publishers, Madras, pp. 103.

Mizuno, M., Yurimoto, H., Yoshida, N., Iguchi, H. and Sakai, Y. 2012. Distribution of Pink pigmented facultative methylotrophs on leaves of vegetables. Biosci. Biotechnol. Biochem. 76, 578580.

Modi, M., Shah, K. S. and Modi, V. V. 1985. Isolation and characterisation of catechol like siderophore from Cowpea Rhizobium RA-1. Arch. Microbiol. 14, 1156-1158.

Neilands, J. B. and Nakumura, K. 1991. Detection, determination, isolation, characterization and regulation of microbial Iron chelates. In: Winkelmann, G. (Ed.). CRC Handbook of Microbial Iron Chelates, Florida, CRC Press, pp: 1-4.

Omer, Z. S., Tombolini, R., Broberg, A. and Gerhardson, B. 2004. Indole-3-acetic acid production by pink-pigmented facultative methylotrophic bacteria. Plant Growth Regul. 43, 93-96.

Radha T. K. 2007. Studies on methylotrophs and their beneficial effects on soybean (Glycine $\max$ (L.) Merrill). M. Sc. (Agri.) Thesis, Univ. Agric. Sci., Dharwad (India).

Reddy, S. 2002. Studies on pink pigmented facultative methylotrophs as a new bioinoculant for groundnut (Arachis 
hypogea L.) M. Sc. (Ag.) Thesis, Tamil Nadu Agril. Uni., Coimbatore.

Reeves, M., Pine, L., Neilands, J. B. and Bullows, A. 1983. Absence of siderophore activity in Legionella $\mathrm{Sp}$. grown in iron deficient media. $J$. Bacteriol. 154, 324-329.

Savitha, P., Sreenivasa, M.N. and Nirmalnath, J. P. 2013. Production of plant growth hormones by pink pigmented facultative methylotrophs. J. Pure and Appl. Microbiol. 7(2), 981-985.

Senthilkumar, M. 2003. Evaluating diazotrophic diversity and endophytic colonization ability Azorhizobium caulinodans and Methylobacerium species in bacterised and biotized rice. Ph. D Thesis, Tamil Nadu Agricultural University, Coimbatore (India).

Seshadri, S., Ignacimuthu, S. and Lakshminarsimhan, C. 2002. Variation in heterotrophic and phosphate solubilizing bacteria from Chennai, southeast coast of India. Indian J. Mar. Sci. 31, 69-72.

Sharma, A. and Johri, N. B. 2003. Growth promoting influence of siderophoreproducing Pseudomonas Strains GRP3A and PRS 9. In Maize (Zea mays L.) under iron limiting conditions. Microbiol. Res. 158, 243-248.
Sheela, R. P., Jones, P.N., Jagadeesh, K. S., Venugopal, C. K. and Gundlur, S. S. 2013. Isolation and characterization of methylotrophs isolated from Coleus forskohlii. Bioinfolet. 10, 59-61.

Thangamani, G. 2005. Studies on facultative methylotrophs for increasing crop production. Ph. D. Thesis, Tamil Nadu Agric. Univ. Coimbatore (India).

Tien, T. M., Gaskins, M. H. and Hubbell, D. H. 1979. Plant growth substances produced by Azospirillum brasilense and their effect on the growth of pearl millet (Pennisetum americanum L.). Appl. Environ. Microbiol. 37, 1016-1024.

Trotsenko, Y. A, Ivanova, E. G. and Doronina, N. V. 2001. Aerobic Methylotrophic bacteria as phytosymbionts. Microbiol. 70, 623-632.

Vaidehi, K. and Sekar, C. 2012. Amino acid conjugated hydroxamate type of siderophore production in Methylobacterium phyllosphaerae MB5. Cibtech J. Microbiol. 1, 24-30.

Whitelaw, M. A., Harden, T. J. and Helyar, K. R. 1999. Phosphate solubilization in solution culture by the soil fungus Penicillium radicum. Soil Biol. Biochem. 31, 655-665.

\section{How to cite this article:}

Savitha Santosh, H.B. Santosh and Sreenivasa, M.N. 2019. Assessment of Native Pink Pigmented Facultative Methylotrophs of Chilli (Capsicum annuum L.) for their Plant Growth Promotional Abilities. Int.J.Curr.Microbiol.App.Sci. 8(01): 1196-1205. doi: https://doi.org/10.20546/ijcmas.2019.801.126 